\title{
INTER-COMPARISONS AMONG PASSIVE MICROWAVE SEA ICE CONCENTRATION PRODUCTS FROM FY-3D MWRI AND AMSR2
}

\author{
Ying Chen ${ }^{1}$, Xi Zhao ${ }^{1, *}$, Meng $\mathrm{Qu}^{1}$, Zian Cheng ${ }^{2}$, Xiaoping Pang ${ }^{1}$, Qing $\mathrm{Ji}^{1}$ \\ ${ }^{1}$ Chinese Antarctic Center of Surveying and Mapping, Wuhan University, China - (chen_ying, xi.zhao, mango, pxp, \\ jjqing)@whu.edu.cn \\ ${ }^{2}$ Changjiang Spatial Information Technology Engineering Co., Ltd., Changjiang Institute of Survey, Planning, Design and Research, \\ China - chengzian@whu.edu.cn
}

Commission III, WG 9

KEY WORDS: Inter-comparisons, Sea Ice Concentration, FY-3D MWRI, AMSR2, Passive Microwave

\begin{abstract}
:
Passive microwave (PM) sensors on satellite can monitor sea ice distribution with their strengths of daylight- and weather-independent observations. Microwave Radiation Imager (MWRI) sensor aboard on the Chinese FengYun-3D (FY-3D) satellites was launched in 2017 and provides continuous observation for Arctic sea ice since then. In this study, sea ice concentration (SIC) product is derived from brightness temperature (TB) data of MWRI, based on an Arctic Radiation and Turbulence Interaction Study Sea Ice (ASI) dynamic tie points algorithm. Our product is inter-compared with a published MWRI SIC product by the Enhanced NASA Team (NT2) algorithm, and three Advanced Microwave Scanning Radiometer 2 (AMSR2) SIC products by the ASI, Bootstrap (BST) and NT2 algorithm. Results show that MWRI SIC are generally higher than AMSR2 SIC and the median of monthly SIC differences are larger in summer. Regional analysis indicates that the smaller differences between AMSR2 SIC and MWRI-ASI SIC occur in the higher SIC areas, and the biases are within $\pm 5 \%$ in the Beaufort Sea, Chukchi Sea, East Siberian Sea, Canadian Archipelago Sea and Central Arctic Sea. There is the smallest SIC difference in the Central Arctic Sea with the biases of $-0.77 \%,-0.60 \%$, and $0.19 \%$ for AMSR2-ASI, AMSR2-BST and AMSR2-NT2, respectively. The trends of MWRI and AMSR2 sea ice extent and sea ice area are consistent with correlation coefficients all greater than 0.997. Besides, mean SIC, sea ice extent and sea ice area of MWRI-ASI are closer to those of AMSR2 than those of MWRI-NT2.
\end{abstract}

\section{INTRODUCTION}

Sea ice concentration (SIC) plays a vital role in climate system. Passive microwave (PM) sensors have been employed to detect sea ice distribution for more than four decades, due to the advantages of daylight- and weather-independent observations (Gloersen et al., 1992; Zabel, Jezek, 1994; Meier et al., 2012). The Advanced Microwave Scanning Radiometer-EOS (AMSRE) aboard on NASA's Aqua satellite was running from 2002 to 2011, and the Advanced Microwave Scanning Radiometer 2 (AMSR2) aboard on the Global Change Observation Mission 1st - Water (GCOM-W1) as follow-on sensor has been operating since 2012 beyond its design lifetime. Several AMSR-E and AMSR2 SIC products have been published. One SIC product data set provided by National Snow and Ice Data Center (NSIDC) was based on the Enhanced NASA Team (NT2) (Markus, Cavalieri, 2009, 2000) algorithm and the AMSR Bootstrap (BST) (Comiso et al., 2003) algorithm. The AMSR-E and AMSR2 brightness temperature (TB) data were also applied to generate SIC product data set using the Arctic Radiation and Turbulence Interaction Study Sea Ice (ASI) algorithm (Spreen et al., 2008) by the University of Bremen, Institute of Environmental Physics (IUP). More recently, two new climate data records called Sea Ice Climate Change Initiative at $25 \mathrm{~km}$ grid spacing (SICCI-25 $\mathrm{km})$ and at $50 \mathrm{~km}$ grid spacing (SICCI-50 km) were based on AMSR-E and AMSR2 TB data from June 2002 onwards, and they were released by the European Space Agency (ESA) Climate Change Initiative (CCI) programme (Lavergne et al., 2019).

\footnotetext{
* Corresponding author
}

The Microwave Radiation Imager (MWRI) sensors aboard on the FengYun-3 (FY-3) series satellites, which are Chinese second generation of sun-synchronous meteorological satellites, have been operating in 2008. The SIC products by applying the NT2 algorithm to TB measured with MWRI were provided by Chinese National Satellite Meteorological Center (NSMC) since June 2011. Moreover, the NSMC published the latest FY-3D MWRI SIC product from July 2018 based on the NT2 algorithm. In this study, an ASI dynamic tie points algorithm is attempted to employ to FY-3D MWRI TB to generate SIC product, which is inter-compared with the published MWRI SIC product by NSMC and three AMSR2 SIC products based on the ASI, BST and NT2 algorithm.

\section{DATA}

The MWRI receives radiation from land covers in five different frequencies between 10 to $89 \mathrm{GHz}$ at both horizontal and vertical polarization. The footprint of the individual measurements varies from $51 \mathrm{~km} \times 85 \mathrm{~km}$ at $10.65 \mathrm{GHz}, 30 \mathrm{~km} \times 50 \mathrm{~km}$ at $18.7 \mathrm{GHz}$, $27 \mathrm{~km} \times 45 \mathrm{~km}$ at $23.8 \mathrm{GHz}$ and $18 \mathrm{~km} \times 30 \mathrm{~km}$ at $36.5 \mathrm{GHz}$ to $9 \mathrm{~km} \times 15 \mathrm{~km}$ at $89 \mathrm{GHz}$. The level 1 MWRI TB data in the year of 2018 were gained from NSMC (http://data.nsmc.org.cn). The AMSR2 TB with the time same were used for bias correction, archived by NSIDC at the dataset AMSR-E/AMSR2 Unified L3 Daily $12.5 \mathrm{~km}$ Brightness Temperatures, Sea Ice Concentration, Motion \& Snow Depth Polar Grids, Version 1 (Meier et al., 2018).

The MWRI SIC product using the NT2 algorithm (MWRI-NT2) with a $12.5 \mathrm{~km}$ spatial resolution was applied to compare 
(http://data.nsmc.org.cn). Three AMSR2 daily SIC products based on the ASI, BST and NT2 algorithms were also used to inter-compare. The ASI SIC product from AMSR2 (AMSR2ASI) at $6.25 \mathrm{~km}$ spatial resolution, version 5.4, was available from the University of Bremen (IUP, https://seaice.unibremen.de), and the BST and NT2 SIC products (AMSR2-BST and AMSR2-NT2) produced by NSIDC have a spatial resolution of $12.5 \mathrm{~km}$ (Meier et al., 2018). All the SIC products were at the polar stereographic projection with the standard latitude at $70^{\circ} \mathrm{N}$. All the AMSR2 SIC products covered the full year of 2018, while the released NT2 SIC product of MWRI only covered the second half year of 2018, starting from $12^{\text {th }}$ July 2018 to $31^{\text {th }}$ December 2018.

\section{METHODS}

\subsection{Bias Correction}

Based on linear regression models, MWRI TB were corrected referring to AMSR2 TB (Meier, Ivanoff, 2017). The linear regression models are written as:

$$
Y=a+b X
$$

where

$$
\begin{aligned}
& a=\text { intercept of the regression line } \\
& b=\text { slope of the regression line } \\
& X=\text { MWRI TB } \\
& Y=\text { AMSR2 TB }
\end{aligned}
$$

Because of large changes in atmospheric and surface properties between swaths, the daily gridded TB images with significant jumps, usually observed in summer months from May to September, were removed. All the TB pairs were sampled from $66.5^{\circ} \mathrm{N}$ to $87^{\circ} \mathrm{N}$ with AMSR2-NT2 SIC greater than $15 \%$ on daily gridded TB images. Yearly models, constructed by the average of daily coefficients calculated for each remaining day and each set of channels, were adopted to correct bias between MWRI and AMSR2 TB data in 2018 (Table 1).

\begin{tabular}{ccc}
\hline Channel & slope & intercept \\
\hline $18.7 \mathrm{~V}$ & 0.900 & 28.014 \\
$23.8 \mathrm{~V}$ & 0.956 & 15.642 \\
$36.5 \mathrm{H}$ & 0.973 & 11.178 \\
$36.5 \mathrm{~V}$ & 0.970 & 12.454 \\
$89 \mathrm{H}$ & 0.972 & 8.625 \\
$89 \mathrm{~V}$ & 0.979 & 8.237 \\
\hline
\end{tabular}

Table 1 . The regression coefficients of yearly models for bias correction at six channels.

\subsection{ASI Dynamic Tie Points Algorithm}

The ASI algorithm, based on the rationale that the polarization difference defined as the difference V-polarization minus $\mathrm{H}$ polarization near $90 \mathrm{GHz}$ is similar for all ice types and much smaller than open water, has been applied to AMSR-E and AMSR2 data (Spreen et al., 2008; Melsheimer, 2019). The SIC is a third-order polynomial of polarization difference, written as:

$$
C=d_{3} P^{3}+d_{2} P^{2}+d_{1} P+d_{0}
$$

where

$$
\begin{aligned}
& C=\text { SIC } \\
& P=\text { polarization difference } \\
& d_{3}, d_{2}, d_{1}, d_{0}=\text { coefficients }
\end{aligned}
$$

The dynamic tie points are introduced to modify the algorithm in this study. The polarization difference of pure pixels with the SIC equal $0 \%$ is open water tie points $p 0$, while those with the SIC equal $100 \%$ is sea ice tie points $p 1$. The initial SIC using AMSRE fixed tie points $p 0=47 \mathrm{~K}$ and $p l=11.7 \mathrm{~K}$ was calculated to collect tie points samples, and the weather filters and maximum ice extent mask were not applied to the initial SIC. For open water tie points, the pixels with initial SIC between $-10 \%$ and $10 \%$ were picked out as samples, which were restricted northern than $50^{\circ} \mathrm{N}$, between $200 \mathrm{~km}$ and $350 \mathrm{~km}$ further away from the monthly NSIDC maximum ice extent climatology (Stroeve, Meier, 2018) and $100 \mathrm{~km}$ off the coastal lines. For sea ice tie points, the pixels with initial SIC larger than $95 \%$ were selected as samples, which were constrained to geographically southern than $87^{\circ} \mathrm{N}$, inside the monthly NSIDC maximum ice extent climatology and 100 $\mathrm{km}$ off the coastal lines. The daily $p 0$ and $p l$ were generated by averaging polarization difference of all selected samples in a central temporal sliding window ( \pm 7 days). The dynamic tie points of MWRI for the full year 2018 are shown in Figure 1. The annual mean of open water tie points $p 0$ is $50.4 \mathrm{~K}$, and that of sea ice tie points $p l$ is $10.0 \mathrm{~K}$.

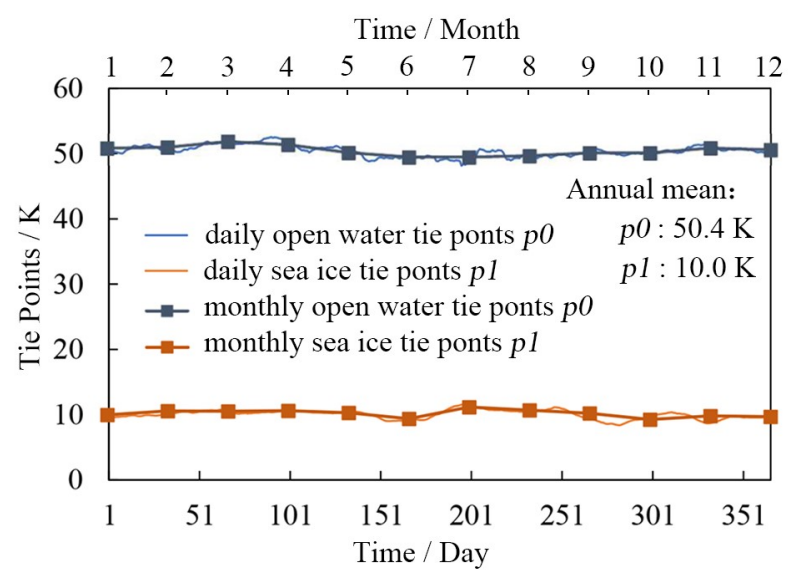

Figure 1. Daily (solid curves) and monthly (solid curves with squares) FY-3D MWRI ASI tie points $p 0$ for open water (blue) and $p 1$ for sea ice (orange) in 2018.

To remove spurious ice over open water due to weather influence, two weather filters were used, one using the gradient ratio of the 36.5 and $18.7 \mathrm{GHz}$ channels, i.e. GR(36.5/18.7) (Gloersen, Cavalieri, 1986) and the other using the gradient ratio of the 23.8 and 18.7 GHz channels, i.e. GR(23.8/18.7) (Cavalieri et al., 1995). The threshold values are 0.045 and 0.04 for GR(36.5/18.7) and the GR(23.8/18.7), respectively. The SIC are set to $0 \%$ where the coincident GR values exceed these thresholds. Since there may be still spurious ice over open water after the weather filters were employed, a maximum ice extent mask during that month in the past 40 years (Stroeve, Meier, 2018) was applied to set the SIC outside the area of maximum ice extent to $0 \%$. The SIC based on an ASI dynamic tie points algorithm was derived from MWRI TB (MWRI-ASI) during the whole year of 2018. The four example days in different seasons are displayed in Figure 2.

For inter-comparisons among these five SIC products temporally and spatially, the AMSR2-ASI SIC was resampled to $12.5 \mathrm{~km}$ spatial resolution, and the same land mask, maximum ice extent mask and pole hole (greater than $87^{\circ} \mathrm{N}$ ) were applied to all the SIC products. All the differences were computed by AMSR2 SIC products minus MWRI SIC products. Sea ice extent and sea ice area as two basic parameters of sea ice distribution were derived 
from these SIC products. Sea ice extent is defined as the sum of the areas of pixels with SIC exceeding $15 \%$. Sea ice area is defined as the integrated sum of each pixel area times the corresponding SIC within the sea ice extent.
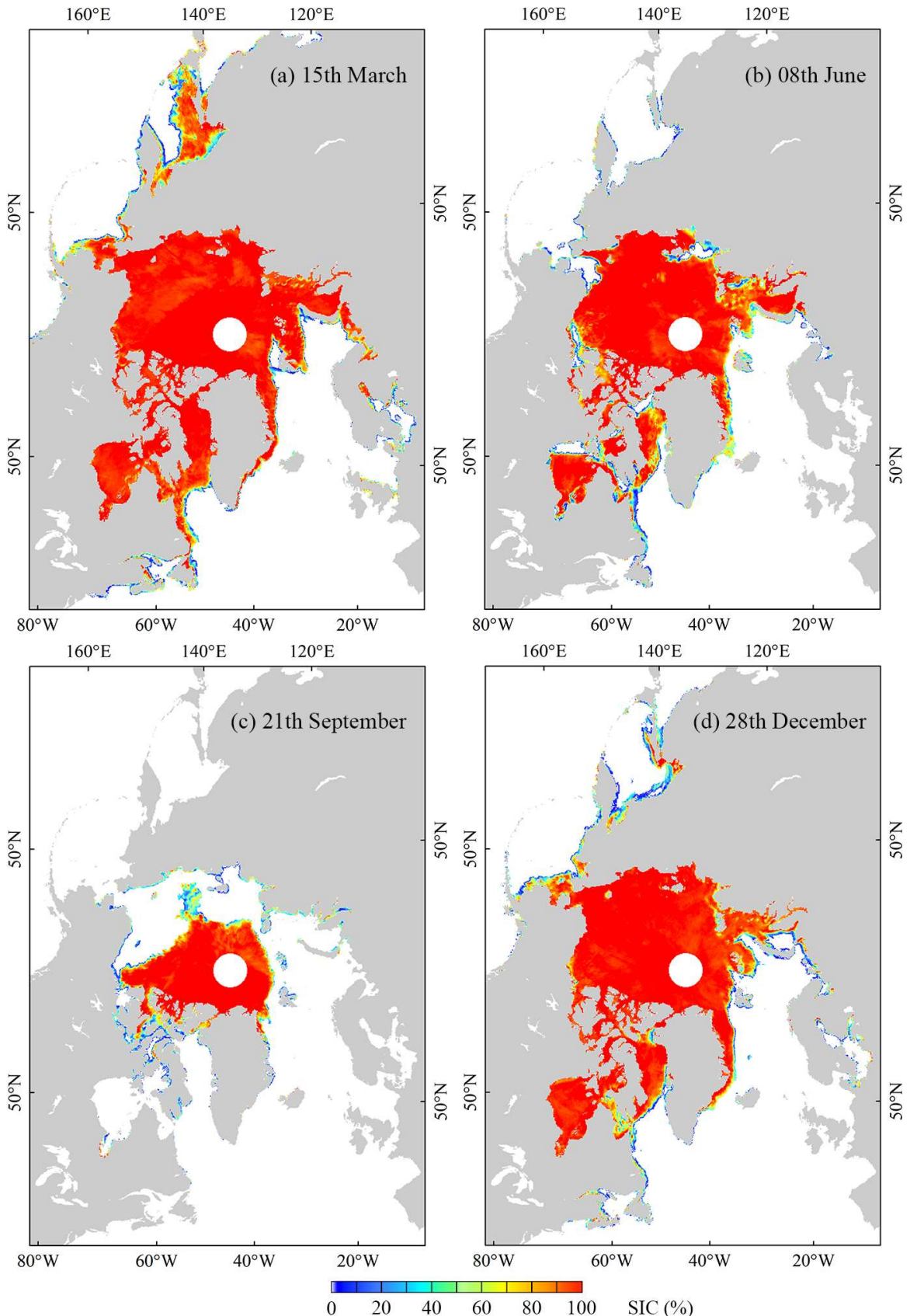

Figure 2. The SIC product derived from FY-3D MWRI TB data by an ASI dynamic tie points algorithm on $15^{\text {th }}$ March, $08^{\text {th }} \mathrm{June}$, $21^{\text {th }}$ September, and $28^{\text {th }}$ December 2018.

\section{RESULT}

The median of monthly differences between AMSR2-ASI, AMSR2-BST, AMSR2-NT2 and MWRI-ASI, MWRI-NT2 SIC were reported in Table 2. Because the released MWRI-NT2 SIC product started only from July 2018, the median of monthly differences between AMSR2 SIC products and MWRI-NT2 were computed from July. In general, the SIC differences show seasonal pattern, and the median of monthly differences are larger in summer. The median of monthly differences between
AMSR2-ASI and MWRI-ASI SIC are $0.00 \%$ except July and August with the values of $-0.82 \%$ and $-0.64 \%$, indicating that MWRI-ASI shows higher SIC in July and August compared to AMSR2-ASI. Comparison between two SIC products based on the NT2 algorithm, the median of monthly differences are $0.00 \%$ in November to December, while MWRI-NT2 SIC is $1.00 \%$ higher than AMSR2-NT2 SIC from July to October. Besides, compared with MWRI-NT2 SIC, the MWRI-ASI SIC has smaller median of monthly differences with AMSR2 SIC products. 


\begin{tabular}{ccccccc}
\hline \multirow{2}{*}{ Month } & \multicolumn{2}{c}{ AMSR2-ASI / \% } & \multicolumn{2}{c}{ AMSR2-BST / \% } & \multicolumn{2}{c}{ AMSR2-NT2 / \% } \\
\cline { 2 - 7 } & MWRI-ASI & MWRI-NT2 & MWRI-ASI & MWRI-NT2 & MWRI-ASI & MWRI-NT2 \\
\hline Jan. & 0.00 & - & 0.00 & - & 0.00 & - \\
Feb. & 0.00 & - & 0.00 & - & 0.00 & - \\
Mar. & 0.00 & - & 0.00 & - & 0.00 & - \\
Apr. & 0.00 & - & 0.00 & - & 0.00 & - \\
May & 0.00 & - & 0.00 & - & 0.00 & - \\
Jun. & 0.00 & - & 0.00 & - & 0.00 & - \\
Jul. & $-\mathbf{0 . 8 2}$ & $\mathbf{- 3 . 5 2}$ & $-\mathbf{1 . 6 1}$ & $\mathbf{- 5 . 0 0}$ & 0.00 & $-\mathbf{1 . 0 0}$ \\
Aug. & $-\mathbf{0 . 6 4}$ & $\mathbf{- 3 . 0 0}$ & $-\mathbf{1 . 0 0}$ & $\mathbf{- 3 . 0 0}$ & $-\mathbf{0 . 3 3}$ & $-\mathbf{1 . 0 0}$ \\
Sep. & 0.00 & $\mathbf{- 0 . 4 7}$ & $-\mathbf{1 . 0 0}$ & $\mathbf{- 1 . 0 0}$ & $-\mathbf{1 . 0 0}$ & $-\mathbf{1 . 0 0}$ \\
Oct. & 0.00 & $\mathbf{- 0 . 1 1}$ & $-\mathbf{0 . 1 3}$ & $\mathbf{- 1 . 0 0}$ & 0.00 & $-\mathbf{1 . 0 0}$ \\
Nov. & 0.00 & $\mathbf{- 0 . 2 9}$ & 0.00 & $-\mathbf{1 . 0 0}$ & 0.00 & 0.00 \\
Dec. & 0.00 & $-\mathbf{0 . 3 3}$ & 0.00 & $-\mathbf{1 . 0 0}$ & 0.00 & 0.00 \\
\hline
\end{tabular}

Table 2. The median of monthly differences between AMSR2-ASI, AMSR2-BST, AMSR2-NT2 and MWRI-ASI, MWRI-NT2 SIC.

Differences of the four SIC products, i.e. AMSR2-ASI, AMSR2BST, AMSR2-NT2 and MWRI-ASI, show spatial variability in each Arctic sea area (Figure 3). Due to the time coverage gap of MWRI-NT2, it was not included in this comparison. It is obvious that regions with higher annually averaged SIC entail smaller SIC differences, such as in the Beaufort Sea, Chukchi Sea, East Siberian Sea, Canadian Archipelago Sea and Central Arctic Sea, with the biases within $\pm 5 \%$ for each AMSR2 SIC products. The Central Arctic Sea has highest averaged annual SIC and smallest differences in SIC $($ Bias $=-0.77 \%,-0.60 \%$, and $0.19 \%$ for AMSR2-ASI, AMSR2-BST and AMSR2-NT2, respectively). In Kara Sea, Bering Sea, Sea of Okhotsk and Barents Sea, where the annual mean SIC are low, the biases are larger, with the largest value of $-22.13 \%$ in Bering Sea for AMSR2-ASI SIC. In the majority of Arctic sea areas, we can see bars representing SIC differences located on the left side which indicates MWRI-ASI SIC are generally larger than AMSR2 SIC products. However, there are five bars of AMSR2-NT2 on the right side, demonstrating that the MWRI-ASI SIC are lower than AMSR2NT2 in the Beaufort Sea, Chukchi Sea, East Siberian Sea, Canadian Archipelago Sea and Central Arctic Sea. The spatial distributions of the SIC differences on four example days in 2018 for AMSR2-ASI, AMSR2-BST, AMSR2-NT2 minus MWRIASI are represented in Figure 4. The differences at ice edge are larger than in inner ice generally. In comparison to AMSR2-ASI SIC, the underestimations of MWRI-ASI occur in pack ice, while the SIC at the ice edge are overestimated by MWRI-ASI.

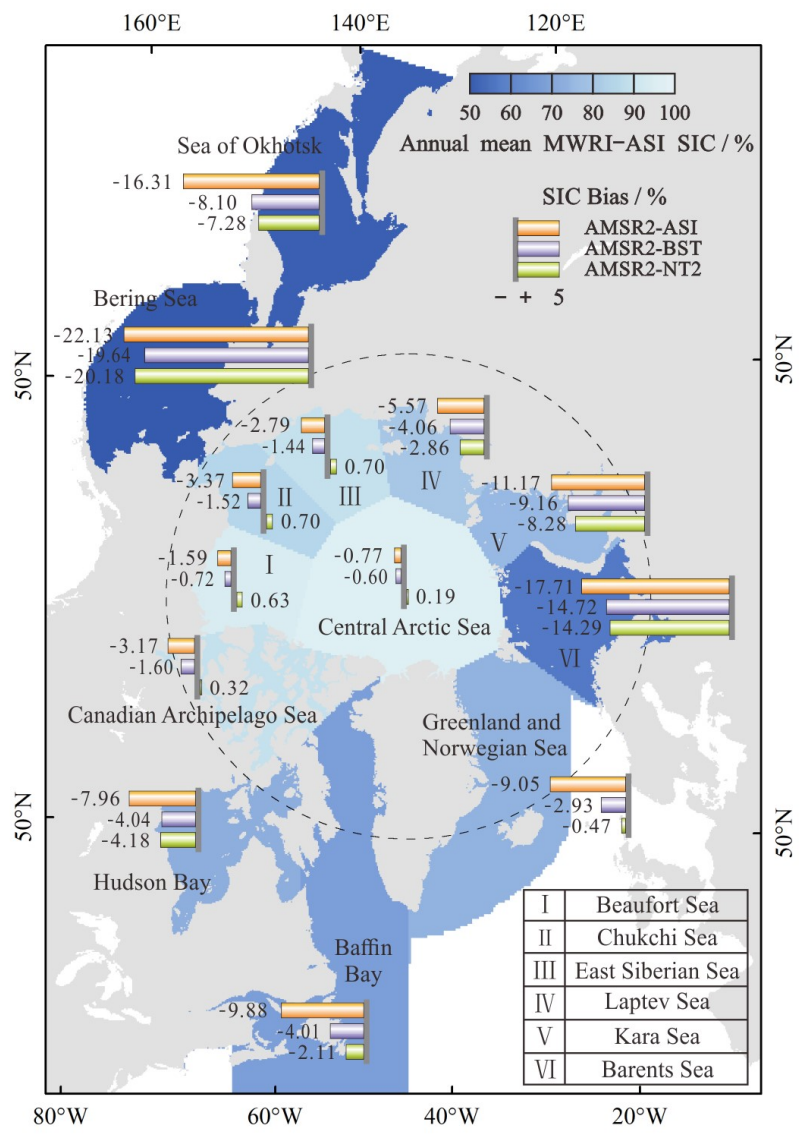

Figure 3. Annual mean MWRI-ASI SIC (The color code gives the SIC between 50 and 100\%). Biases (The left is negative, and the right is positive) between AMSR2-ASI (orange), AMSR2BST (purple), AMSR2-NT2 (green) and MWRI-ASI SIC in Arctic sea area in 2018. The dash line indicates the Arctic Circle. 


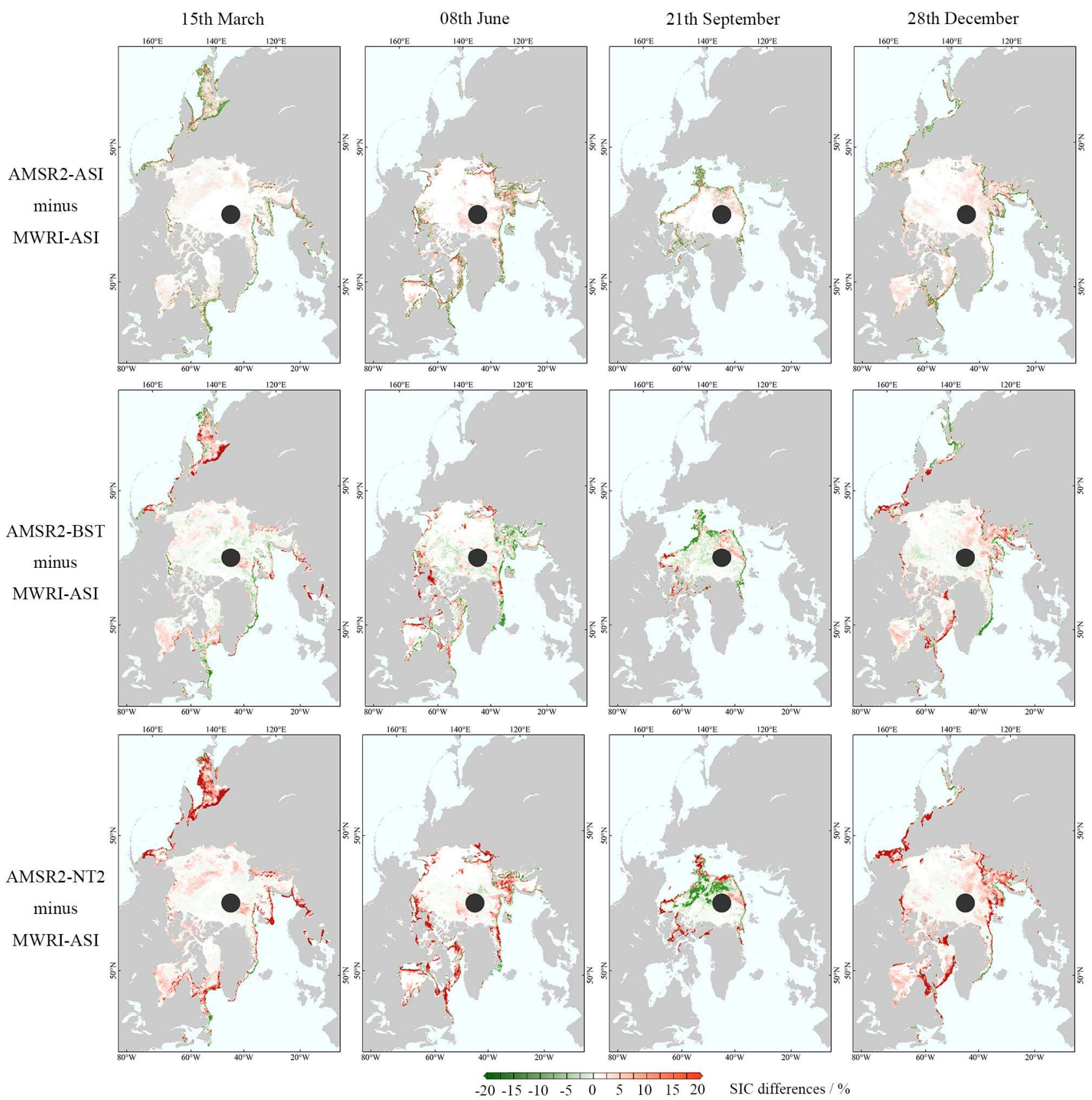

Figure 4. Differences maps of SIC on $15^{\text {th }}$ March, $08^{\text {th }}$ June, $21^{\text {th }}$ September, and $28^{\text {th }}$ December 2018 of AMSR2-ASI minus MWRIASI (top), AMSR2-BST minus MWRI-ASI (middle) and AMSR2-NT2 minus MWRI-ASI (bottom).

Daily sea ice extent and daily sea ice area for the four SIC products: AMSR2-ASI, AMSR2-BST, AMSR2-NT2 and MWRI-ASI, were inter-compared in the full year of 2018 (Figure 5). Quantitative inter-comparisons of sea ice extent and sea ice area calculated from AMSR2-ASI, AMSR2-BST, AMSR2-NT2 and MWRI-ASI, MWRI-NT2 were made during the overlapped period (Table 3). The patterns observed in Figure $5 \mathrm{a}$ and $5 \mathrm{c}$ are almost same. The trends of sea ice extent and sea ice area derived from the three AMSR2 SIC products are very consistent with those from the two MWRI SIC products, with correlation coefficients all greater than 0.997. Differences of sea ice extent and sea ice area in Figure $5 \mathrm{~b}$ and $5 \mathrm{~d}$ demonstrate a similar pattern for three AMSR2 SIC products respectively. The curves almost locate below the reference line of MWRI-ASI except the
AMSR2-NT2 curves for sea ice area during winter period (see Figure 5d). For both sea ice extent and sea ice area, the biases are negative between AMSR2-ASI and MWRI-ASI, indicating that MWRI-ASI gives larger sea ice extent and sea ice area than AMSR2-ASI. For sea ice extent, AMSR2-BST shows the lowest absolute biases with MWRI-ASI and MWRI-NT2 with the values of $-0.29 \times 10^{6} \mathrm{~km}^{2}$ and $-0.39 \times 10^{6} \mathrm{~km}^{2}$, respectively. There are the lowest absolute biases between AMSR2-NT2 and two MWRI sea ice area, with the values of $-0.13 \times 10^{6} \mathrm{~km}^{2}$ and $-0.44 \times 10^{6} \mathrm{~km}^{2}$ for MWRI-ASI and MWRI-NT2, respectively. Compared to sea ice extent and sea ice area derived from three AMSR2 SIC products, the biases of MWRI-ASI are around 0.10 $\times 10^{6} \mathrm{~km}^{2}$ and $0.30 \times 10^{6} \mathrm{~km}^{2}$ lower for sea ice extent and sea ice area than MWRI-NT2, respectively. 

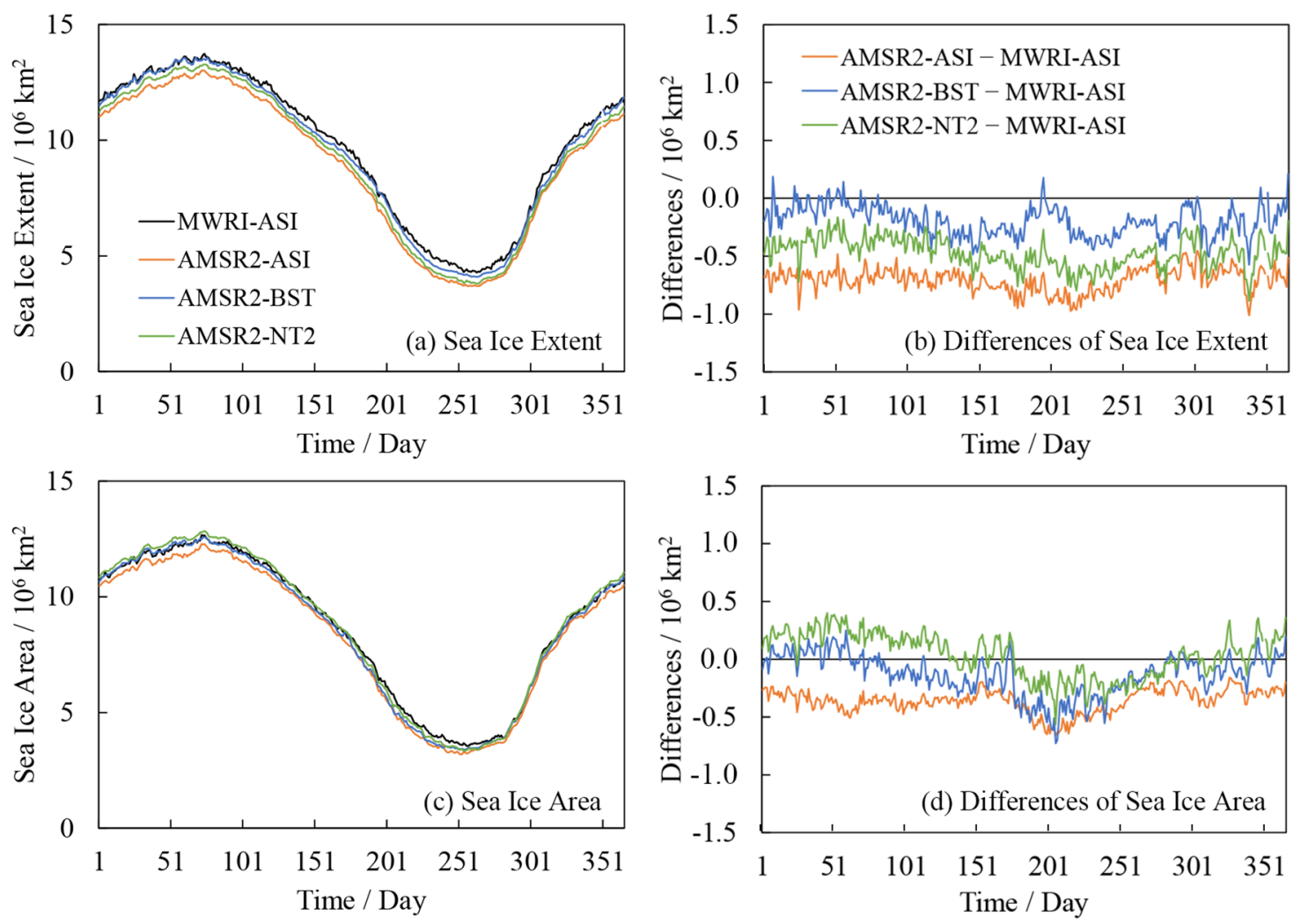

Figure 5. Daily (a) sea ice extent, (c) sea ice area of MWRI-ASI (black), AMSR2-ASI (orange), AMSR2-BST (blue) and AMSR2NT2 (green). Differences of (b) sea ice extent, (d) sea ice area between AMSR2-ASI (orange), AMSR2-BST (blue), AMSR2-NT2 (green) and MWRI-ASI in the full year of 2018.

\begin{tabular}{lcccc}
\hline \multirow{2}{*}{ SIC Products } & \multicolumn{2}{c}{ Bias } & \multicolumn{2}{c}{ Correlation } \\
\cline { 2 - 5 } & MWRI-ASI & MWRI-NT2 & MWRI-ASI & MWRI-NT2 \\
\hline \multicolumn{5}{c}{ Sea Ice Extent / $10^{6} \mathrm{~km}^{2}$} \\
AMSR2-ASI & -0.83 & -0.93 & 0.9988 & 0.9986 \\
AMSR2-BST & -0.29 & -0.39 & 0.9986 & 0.9991 \\
AMSR2-NT2 & -0.61 & -0.70 & 0.9987 & 0.9990 \\
\hline \multicolumn{5}{c}{ Sea Ice Area / $10^{6} \mathrm{~km}^{2}$} \\
AMSR2-ASI & -0.45 & -0.77 & 0.9987 & 0.9988 \\
AMSR2-BST & -0.23 & -0.55 & 0.9977 & 0.9987 \\
AMSR2-NT2 & -0.13 & -0.44 & 0.9989 & 0.9997 \\
\hline
\end{tabular}

Table 3. Biases and correlations between AMSR2-ASI, AMSR2-BST, AMSR2-NT2 and MWRI-ASI, MWRI-NT2 sea ice extent, sea ice area during 12th July to 31 th December in 2018.

\section{CONCLUSION}

This study generated SIC by an ASI dynamic tie-point algorithm from newly released FY-3D MWRI TB data. Inter-comparisons were made among two FY-3D MWRI and three AMSR2 SIC products. The negative median of monthly differences show that AMSR2 SIC are lower than MWRI SIC. The SIC differences are seasonal, with the median of monthly differences larger in summer and $0.00 \%$ in winter. Regional analysis indicates that SIC differences between AMSR2-ASI, AMSR2-BST, AMSR2NT2 and MWRI-ASI are small in high SIC regions, with the biases within $\pm 5 \%$ in the Beaufort Sea, Chukchi Sea, East
Siberian Sea, Canadian Archipelago Sea and Central Arctic Sea. The Central Arctic Sea has the smallest SIC differences with the biases of $-0.77 \%,-0.60 \%$, and $0.19 \%$ for AMSR2-ASI, AMSR2-BST and AMSR2-NT2, respectively. The trends of sea ice extent and sea ice area are very similar for MWRI and AMSR2, with correlation coefficients all greater than 0.997 . Mean SIC, sea ice extent and sea ice area of MWRI-ASI are more consistent with those of AMSR2 than MWRI-NT2. The above results suggest that our MWRI-ASI SIC product may outperform published MWRI-NT2, and more detailed validation should be done to confirm these primary results. 


\section{ACKNOWLEDGEMENTS}

This research has been supported by the National Key Research 664 and Development Program of China (grant nos. 2018YFC1407100, 2018YFA0605903) and the National Natural Science Foundation of China (grant nos. 41876223).

\section{REFERENCES}

Cavalieri, D. J., Germain, K. M. S., Swift, C. T., 1995. Reduction of weather effects in the calculation of sea-ice concentration with the DMSP SSM/I. Journal of Glaciology, 41(139), 455-464.

Comiso, J. C., Cavalieri, D. J., Markus, T., 2003. Sea ice concentration, ice temperature, and snow depth using AMSR-E data. IEEE Transactions on Geoscience and Remote Sensing, 41(2), 243-252.

Gloersen, P., Campbell, W. J., Cavalieri, D. J., Comiso, J. C., Parkinson, C. L., and Zwally, H. J. 1992. Arctic and Antarctic sea ice, 1978-1987: Satellite Passive-Microwave Observations and Analysis.

Gloersen, P., Cavalieri, D. J., 1986. Reduction of weather effects in the calculation of sea ice concentration from microwave radiances. Journal of Geophysical Research: Oceans, 91(C3), 3913-3919.

Lavergne, T., Sorensen, A., Kern, S., Tonboe, R., Notz, D., Aaboe, S., Bell, L., Dybkjaer, G., Eastwood, S., Gabarro, C., 2019. Version 2 of the EUMETSAT OSI SAF and ESA CCI seaice concentration climate data records. The Cryosphere, 13(1), 49-78.

Markus, T., Cavalieri, D. J., 2009. The AMSR-E NT2 sea ice concentration algorithm: Its basis and implementation. Journal of the Remote Sensing Society of Japan, 29(1), 216-225.
Markus, T., Cavalieri, D. J., 2000. An enhancement of the NASA Team sea ice algorithm. IEEE Transactions on Geoscience and Remote Sensing, 38(3), 1387-1398.

Meier, W. N., Ivanoff, A., 2017. Intercalibration of AMSR2 NASA Team 2 Algorithm Sea Ice Concentrations With AMSRE Slow Rotation Data. IEEE Journal of Selected Topics in Applied Earth Observations and Remote Sensing, 10(8), 39233933.

Meier, W. N., Markus, T., Comiso, J. C., 2018. AMSRE/AMSR2 Unified L3 Daily $12.5 \mathrm{~km}$ Brightness Temperatures, Sea Ice Concentration, Motion \& Snow Depth Polar Grids, Version 1. Boulder, Colorado USA. NASA National Snow and Ice Data Center Distributed Active Archive Center. doi: https://doi.org/10.5067/RA1MIJOYPK3P.

Meier, W. N., Stroeve, J., Barrett, A. P., Fetterer, F., 2012. A simple approach to providing a more consistent Arctic sea ice extent time series from the 1950 s to present. The Cryosphere, 6(6), 1359-1368.

Melsheimer, C., 2019. ASI Version 5 Sea Ice Concentration User Guide. Institute of Environmental Physics, University of Bremen.

Spreen, G., Kaleschke, L., Heygster, G., 2008. Sea ice remote sensing using AMSR - E $89-\mathrm{GHz}$ channels. Journal of Geophysical Research: Oceans, 113(C2), 2008.

Stroeve, J., Meier, W. N., 2018. Sea Ice Trends and Climatologies from SMMR and SSM/I-SSMIS, Version 3. Boulder, Colorado USA. NASA National Snow and Ice Data Center Distributed Active Archive Center. doi: https://doi.org/10.5067/IJ0T7HFHB9Y6.

Zabel, I. H. H., Jezek, K. C., 1994. Consistency in long-term observations of oceans and ice from space. Journal of Geophysical Research, 99(C5), 10109-10120. 